\title{
RECONSTRUCTION OF HISTORICAL GEODETIC SYSTEMS FOR THEIR IMPLEMENTATION IN REPROJECTION ALGORITHMS
}

\author{
V. Baiocchi ${ }^{1}$, M. Deligios ${ }^{2}$, F. Giannone ${ }^{3}$, G. Timar $^{4}$ \\ ${ }^{1}$ DICEA, Sapienza University of Rome, Via Eudossiana 18, 00184 Rome (Italy), valerio.baiocchi@uniroma1.it \\ ${ }^{2}$ GloboGIS s.r.l, Viale Europa, 17/B - 24048 Treviolo (BG), info@globogis.it \\ ${ }^{3}$ Engineering Faculty, Niccolò Cusano University, Via Don Carlo Gnocchi 3, 00166 Rome (Italy), francesca.giannone@unicusano.it \\ ${ }^{4}$ Department of Geophysics and Space Science, Eötvös University, Budapest Hungary- timar@caesar.elte.hu
}

Commission VI, WG VI/4

KEY WORDS: Historical cartography, Datum transformation, GIS, cadastre, Burša-Wolf

\begin{abstract}
:
Historical cartography is an important source of geographic information for diachronic studies.

The Italian geodetic datum from the second half of the 20th century are well known and used, while the reference systems used previously do not have a certain documentation also because they were developed by the military geographical institute, which at the time was a uniquely military body with the related problems of confidentiality.

The reconstruction of the datum of each single historical map is a fundamental process, in order to be able to correctly compare historical information with the current ones, but it is complex because of the scarce information available on the type of datum and cartographic projection used for the production of the map.

The reconstruction of the ancient morphology of an area, such as that of 1893 Forma urbis map or the pre-reclamation maps of Agro Pontino, is of fundamental importance for various studies on geomorphological changes of the territory, including, for example, the reconstruction of diverted and/or covered watercourses.

Many of the Italian historical maps have been referred to the ellipsoid of Bessel with different orientations that in many cases are the same used previously or simultaneously for public purposes including, in particular, the drafting of the cadastral cartography.
\end{abstract}

\section{INTRODUCTION}

Not much is officially known about the geodetic systems (more than one) adopted in the IGM works at the end of the last nineteenth century or early '900 (Mori, 1922). The main definitions use the Bessel ellipsoid oriented to Genoa (for central-northern Italy, including the whole of Umbria), Castanea delle Furie (for southern Italy) or Roma M. Mario (for part of central Italy) (Radicioni \& Stoppini, 2019).

On these datums was based the realization of the cadastral network for which the fundamental meridian is the one passing through the respective point of emanation (Genoa, M.Mario or Castanea delle Furie).

The realization of the cadastral network took place through the network of cadastral triangulation which is based on the IGM network of I, II and III order integrated by a cadastral network of refining divided into three further orders called network, subnet and detail.

The IGM fourth order was discarded because it did not have sufficient accuracy for the map of the Land Registry (which is at the scale 1:2000, while the IGM map reaches at most the scale 1:25000). The networks from the first to the third order IGM were then used by the Land Registry with the values of the coordinates that they had at the time of formation of the Land Registry (between the late ' 800 and early '900).

The IGM subsequently adopted the datum Roma 40 and carried out numerous measurements, corrections and updating calculations of the network that have not been received by the Cadastre, so it must always to be kept in mind that the geometry of the cadastral network may differ (in some areas even significantly) from that of the IGM network of the time and certainly from the subsequent (Rome 40, IGM95)
For this reason, reconstructing the transformations of datum between the cadastral systems and the modern ones can be of great utility also for the transformations of the national historical cartographies (Barbarella 2009; Bendea 2011; Camiciottoli 2008, Cina 2012).

It should be noted in this regard, that recently the Italian cadastre has put a procedure to transform its maps from its original coordinate system to the most recent materialization of WGS84 (RDN2008) but the parameters of these transformations are not public and, while giving good results overall, have been observed locally of several meters whose cause is not entirely clear.

\subsection{Italian Cadastre}

The Italian cadastral history is very complex because, before the unification process, each incoming pre-unification State had it its own cadastre. Each cadastral system was characterized by different cartographic projection and data quality; some were geometric while others descriptive and based on a declaration of ownership by the heads of families.

The coexistence on Italian territory of different official cadastral registers caused a great inhomogeneity in the method of determining taxes.

The current Italian cadastre was born with the Messedaglia Law $\mathrm{n}^{\circ} 3682$ of 1886 (also called "perequazione fondiaria" law) with the purpose of eliminating the pre-unitary inhomogeneity through the establishment of a single geometric-parcel cadastre for the whole national territory. They represent the result of the largest scale survey of on the whole national territory. Because of their large scale, their realization was extremely expensive and the updating of the cadastre claim considerable funds from 
the state budgets. That is why the coordinate system, the geodetic basis of a cadastral work, is rarely changed.

The cadastral maps were drawn up mainly using the Cassini Soldner (C.S.) projection and completely cover the national territory, obtaining about 310,000 cadastral maps with 849 different origins. In particular, there are 31 origins for the territories with great extension (called "grandi origini") and 818 origins for the territories of small extension (called "piccole origini"). The ellipsoid adopted for cadastral datum was the Bessel ellipsoid oriented to: "Castanea delle Furie", for many provinces south of Rome, to Rome "Monte Mario", for some areas of central Italy and Genoa, for the territories to the north. Of course, the geodetic bases of the cadastral datum is the trigonometric network, connected to the trigonometric networks of the Italian Institute of Military Geography (Istituto Geografico Militare; I.G.M) but, in some cases cadastral surveys was carried out before those of the Italian Institute of Military Geography. Consequently, in the cadastral network approximate values for the coordinates of the IGM trigonometric vertices have sometimes been assumed; therefore one of the fundamental problems for cadastral maps is related to inconsistency with the official IGM information.

Since 1942 began the conversion of the cadastral cartography from Cassini-Soldner to Gauss-Boaga cartographic representation, but this operation has been developed only in some provinces. In the last years a complex work of reprojection of the whole cadastral cartography in the system obligatorily foreseen by the specific ministerial regulation of 2008 has been started (Barbarella 2014)

\section{PROCEDURE}

\subsection{Trigonometric and "fiduciali" points}

The data for the estimation of preliminary parameters for the transformation from the C.S. reference system to the most recent UTM-WGS84-ETRS89 have been extrapolated from the site: "www.globogis.it/fiduciali.it".

Firs of all an analysis of the available data was carried out with the aim of: validating the effective association between "fiduciali" and trigonometric points and obtaining a set of points without outliers and valid as a set of "double points" to be used in the least squares estimation of the roto-translation parameters between the cadastral C.S. and the UTM-WGS84ETRS89 coordinates. The analysis was carried out by transforming in the UTM-WGS84-ETRS89 system the coordinates of each single of the "fiduciali" points and then comparing the result with the coordinates of the most probable associated trigonometric. The useful data for the analysis was simply the difference between the coordinates of the "fiduciali" and the coordinates of the associated trigonometric, both referred to the same datum. The software used for the transformation is Cartlab (Surace 2008) and Geotrasformer (Baiocchi 2017).

In the selected test area, the territory of the metropolitan city of Roma Capitale, 463 "fiduciali" points and, of course, 463 trigonometric points were extracted from the database (figure 1). The points to be included in the estimate were selected on the basis of a simple analysis of the differences, here adopted instead of more rigorous analysis of "data snooping" (Barbarella 2006). The verification showed that only 232 fiduciali trigonometric pairs had a value of less than about $2.5 \mathrm{~m}$ (table 1) while the remaining 231 points exceed this threshold, even reaching the order of $90-100$ meters.

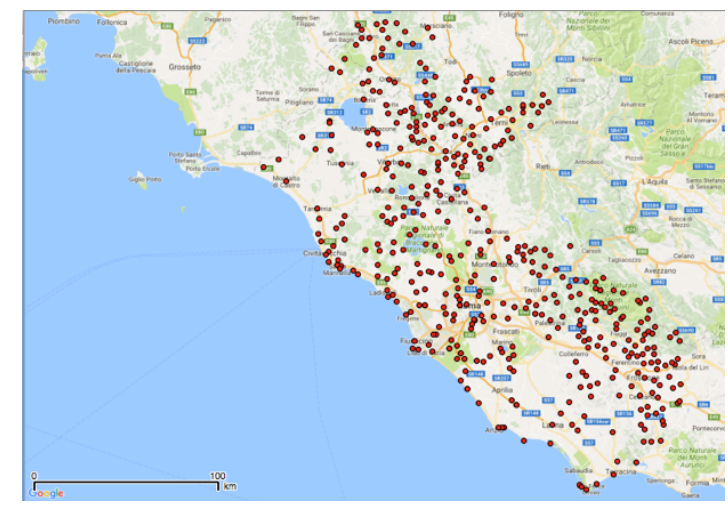

Figure 1. Point distribution in "Città metropolitana di Roma Capitale" area

\begin{tabular}{|l|c|l|}
\hline Points & $\mathrm{N}^{\circ}$ & residual \\
\hline total & 463 & -- \\
LSP - Least Square Point & 232 & $<2.5 \mathrm{~m}$ \\
rejected & 231 & $>2.5 \mathrm{~m}$ \\
\hline
\end{tabular}

Table 1. Point in "Città metropolitana di Roma Capitale" area

\subsection{Burša-Wolf parameters estimation}

The points selected for the estimation (LSP - Least Square Points) of the transformation parameters between the two datum, for the selected area Bessel M.Mario and WGS84ETRS89, coincide with the 232 points that have a residual value less than about $2.5 \mathrm{~m}$.

The estimate was made using two independent software: the scientific software described in previous research (Timár 2017) and developed to estimate global parameters useful mainly for the automatic georeferencing of historical cadastral maps (Timár 2011; Timár 2013), and the commercial software Killet (http://www.killetsoft.de/homee.htm).

The parameters, estimated with both software, have been used in QGIS creating two custom reference systems; in this way it has been possible to create a simple, fast and semi-automatic procedure for the transformation from the cadastral datum to the WGS84-ETRS89 datum of a large number of points.

Once the custom system has been configured, Q-GIS automatically returns each vector or raster file to the default reference system for the project (e.g. UTM-WGS84-ETRS89). Figure 2 shows the QGIS string with the parameters estimated by the scientific software.

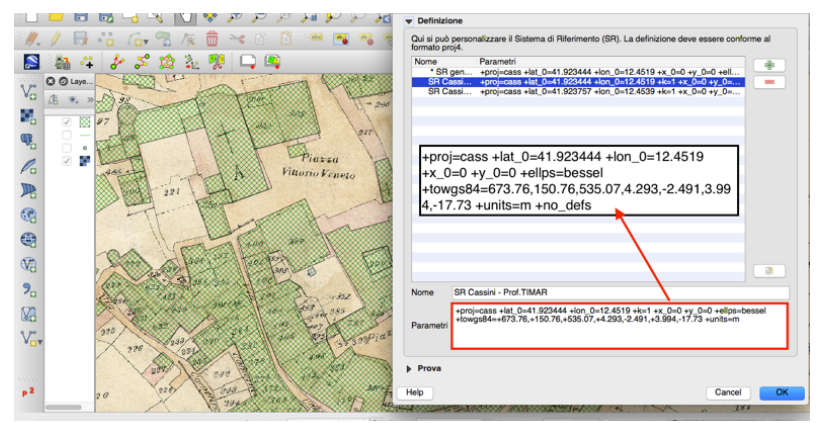

Figure 2. Estimated parameters - scientific software 


\begin{tabular}{|lcccc|}
\hline & \multicolumn{2}{c|}{ scientific software } & \multicolumn{2}{c|}{ Killet software } \\
\hline & $\mathrm{N}[\mathrm{m}]$ & $\mathrm{E}[\mathrm{m}]$ & $\mathrm{N}[\mathrm{m}]$ & $\mathrm{E}[\mathrm{m}]$ \\
$\max$ (absolute value) & 2.086 & 1.546 & 1.687 & 2.387 \\
dev.st & 0.494 & 0.464 & 0.494 & 0.465 \\
\hline
\end{tabular}

Table 2. Residual analysis - 232 LSP

Transforming the 232 LSP points into a QGIS environment and analysing the residual value on the coordinates the accuracy of the estimate parameters have evaluated; the results, obtained with both sets of parameters, are summarised in Table 2

\section{ANALYSIS OF THE REPROJECTION OF TWO ORIGINAL PLANT CADASTRAL MAPS}

The procedure was evaluated considering two test areas, representing quite different situations within the area of competence of the Metropolitan City of Rome Capital: the area around Piazza del Colosseo in the center of Rome and the historic center of Castelnuovo di Porto, small town about $30 \mathrm{~km}$ from the capital.

The analisys was lead considering two raster file of cadastral maps in order to exclude the uncontrollable effects of vectorization on products already vectorialized

The two raster maps were georeferenced and re-sampled in Cassini-Soldner according to the most established and documented procedures in the literature (Baiocchi, 2010; Baiocchi, 2013; Brigante, 2014).

A first evaluation of the accuracy of the estimated parameters was carried out in QGIS: the georeferenced plant maps were transformed into WGS84-ETRS89 and compared with modern cartographic products: for the map of Piazza del Colosseo the comparison was made with a vector cartography 1:2000, while for the Castelnuovo area the CTR 1:5000 was used.

The comparison with the modern cartography was made on the cadastral maps transformed both with the parameters estimated by the scientific software (figure 3sx) and with those estimated by the Killet software (figure $3 \mathrm{dx}$ ).

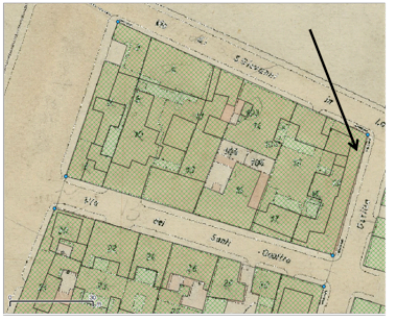

Parametri: software scientifico

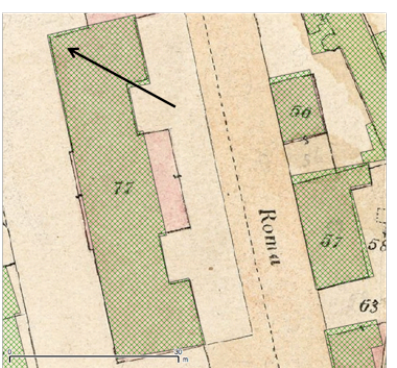

Figure 3. Comparison between cadastral maps and modern cartography. Up: Piazza del Colosseo. Bottom: Castelnuovo di Porto

To conclude this preliminary analysis of accuracy, 40 points were collimated on each cadastral map (figure 4) and the coordinates obtained were compared with those of the same collimation details on the two modern maps. This last analysis was carried out considering only the cadastral maps transformed with the parameters of the scientific software.
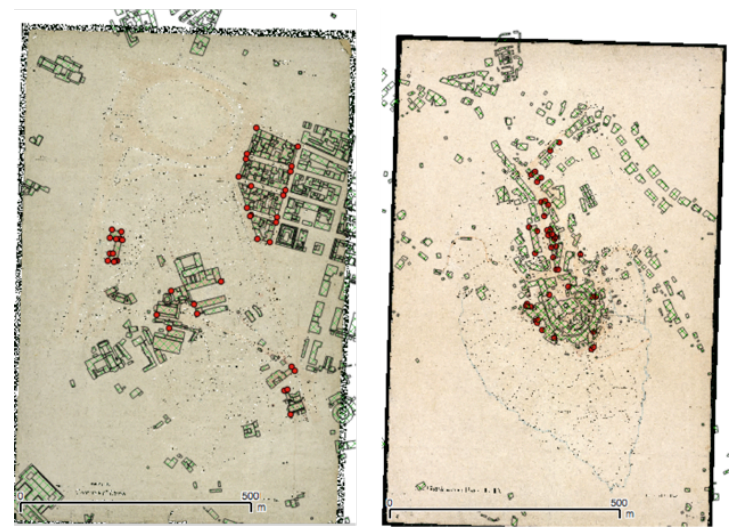

Figure 4. Point distribution: Piazza del Colosseo (left) and Castelnuovo di Porto (right)

\begin{tabular}{|lcccc|}
\hline & \multicolumn{2}{c}{$\begin{array}{c}\text { Piazza del } \\
\text { Colosseo }\end{array}$} & \multicolumn{2}{c|}{$\begin{array}{c}\text { Castelnuovo di } \\
\text { Porto }\end{array}$} \\
\hline & $\mathrm{N}[\mathrm{m}]$ & $\mathrm{E}[\mathrm{m}]$ & $\mathrm{N}[\mathrm{m}]$ & $\mathrm{E}[\mathrm{m}]$ \\
Mean & 0.104 & 0.177 & -0.379 & 0.026 \\
Max shift & 2.170 & 1.810 & 1.253 & 2.197 \\
dev.st & 0.572 & 0.541 & 0.444 & 0.568 \\
\hline
\end{tabular}

Table 3. Shift analysis - 40 points - parameters: scientific software

\section{COMPARISON WITH HISTORICAL TECNICAL MAPS}

An example of historical maps at 1:5000 scale produced by the IGM between 1927 and 1930, before the fascist reclamation works, are the Agro Pontino maps (area located about $50 \mathrm{Km}$ to the South of Rome) (figure 5). Unfortunately, in the Agro Pontino pre-reclamation maps the geodetic datum and the cartographic projection are unknown; only the longitude origin is given (Baiocchi et al., 2019).

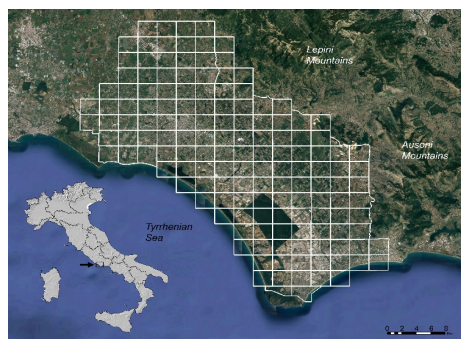

Figure 5. Pre-reclamation maps

The parameters estimated and tested using the cadastral information were used for the transformation of historical prereclamation maps of Agro Pontino.

The transformation accuracy is tested using an independent set of points identified on the transformed pre-reclamation maps and on Regional technical cartography CTR - Lazio Region, Scale 1:5000

The main problem is linked to a correct identification of points recognizable on both the pre-reclamation maps and present cartography, in fact the heavy geomorphological modifications which started with the reclamation scheme and the very few 
human structures present in the 1930s in the Agro Pontino both make the point identification very difficult.

In the pre-reclamation maps of Sezze town, 20 points were identified to perform a preliminary accuracy analysis (table 4) that highlight a planimetric accuracy maximum value of $7.5 \mathrm{~m}$.

\begin{tabular}{|ccc|}
\hline Check Points & $\begin{array}{c}\text { East } \\
{[\mathbf{m}]}\end{array}$ & $\begin{array}{c}\text { North } \\
{[\mathbf{m}]}\end{array}$ \\
\hline mean & 0.199 & 2.682 \\
st.dev & 2.977 & 2.592 \\
max & 5.740 & 0.520 \\
min & -4.947 & -7.570 \\
\hline
\end{tabular}

Table 4. Shift analysis - 20 points - parameters: scientific software

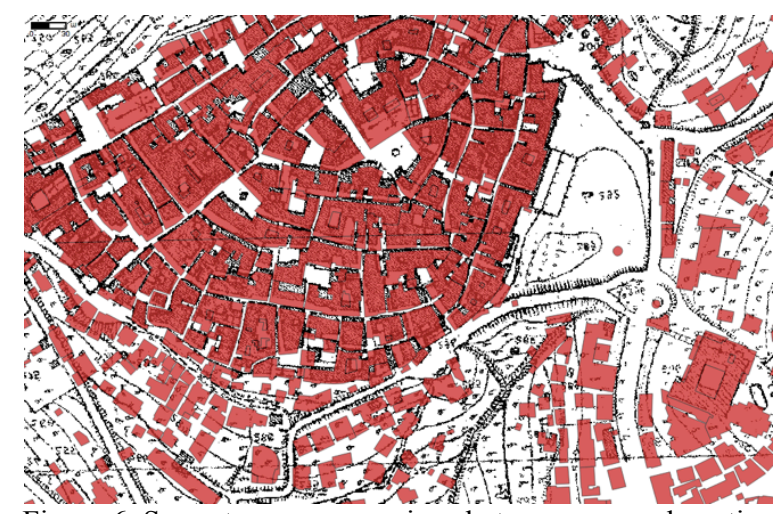

Figure 6. Sezze town - comparison between pre-reclamation maps and CTR (in red)

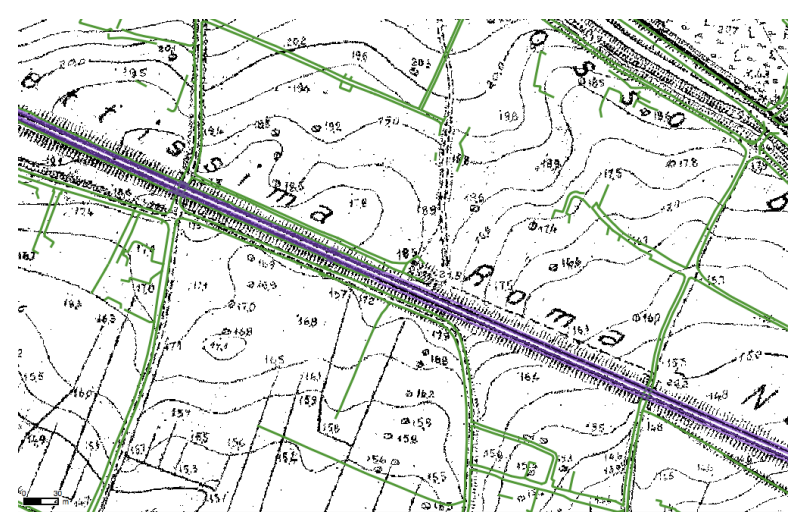

Figure 7. Railway "Direttissima Roma-Napoli"

completed in 1927 and unchanged during the years.

- comparison between pre-reclamation maps and CTR (in violet)

\section{CONCLUSION AND FURTHER DEVELOPMENTS}

This work has allowed us to make an initial assessment of the real utility of the use of cadastral maps to reconstruct the geodetic datum of other maps of the same period: late nineteenth century, early twentieth century.

The experiments showed results compatible with the scales of the maps but subsequent and more extensive tests will certainly be carried out with maps of great historical interest such as the Forma Urbis of Rome.

\section{REFERENCES}

Baiocchi V., Alessandri L., Giannone F., 2019, Pre-Bonifica maps of the Agro Pontino: an assessment, proceedings 2018
IEEE International Conference on Metrology for Archaeology and Cultural Heritage, October 2018, Cassino, Italy

Baiocchi V., Camuccio P., Zagari M., Ceglia A., Del Gobbo S., Purri F., Cipollini L., Liso L., 2017, Development of a geographical database of a district area in Open Source environment, Bollettino GEAM, on this same volume

Baiocchi, V., Lelo, K., Milone, M.V., Mormile, M., 2013, Accuracy of different georeferencing strategies on historical maps of Rome, Geographia Technica

Baiocchi, V. \& Lelo, K., 2010. Accuracy of 1908 high to medium scale cartography of Rome and its surroundings and related georeferencing problems. Acta Geodaetica et Geophysica Hungarica, 45 (1), 97-104. DOI: 10.1556/AGeod.45.2010.1.14

Baglioni, R., Baiocchi, V., Dominici, D., Milone, M. V. \& Mormile, M., 2013. Historic cartography of L'Aquila city as a support to the study of earthquake damaged buildings.Geographia Technica. 1-9.

Barbarella, M. 2014. Digital Technology and Geodetic Infrastructures in Italian Cartography. Città e Storia IX (1): 91110. Università Roma Tre-CROMA.

Barbarella M., Radicioni F., Sansò F. 2009. lo sviluppo delle tecnologie per le reti geodetiche, CISIS

Barbarella M., Gordini C. 2006. Kinematic GPS survey as validation of LIDAR strips accuracy. Annals of Geophysics, 49 (1), pp. 21-23

Bendea J.H., Chiaffrino A., Cina A., Ferrante F.C., Garretti 1., Manzino A.M., Pipino M., Piras M., Porporato C., Siletto G.B. 2011. La mappa catastale nel sistema di riferimento WGS84, in regione Piemonte. Atti 15a Conferenza Nazionale ASITA Reggia di Colorno 15-18 novembre 2011

Brigante R., Radicioni F., 2014. georeferencing of historical maps: gis technology for urban analysis, Geographia Technica, Vol. 09, Issue 1, pp 10 to 19

Camiciottoli F., Surace L., 2008, Trasformazioni planimetriche di coordinate in ambito catastale: il caso della provincia di Arezzo. Atti 12a Conferenza Nazionale ASITA - L'Aquila 2124 ottobre 2008

Cina A., Ferrante F.C., Piras M., Porporato C. 2012. La trasformazione dal DATUM catastale ai DATUM Roma 1940 e ETRF2000. TERRITORIO ITALIA, vol. 01/12, pp. 107-119. ISSN 2240-7707

Killet software: http://www.killetsoft.de/homee.htm

Mori A., 1922. La cartografia ufficiale in Italia e l'Istituto Geografico Militare - Nel cinquantenario dell'Istituto Geografico Militare (1872-1922). Istituto Geografico Militare, Stabilimento Poligrafico per l'Amministrazione della Guerra, Roma, 425p.

Timár, G., Baiocchi, V., Lelo K., 2011, Geodetic datums of the Italian cadastral systems Geographia Technica 
Timár, G., Baiocchi, V., Lelo, K. 2013 A new methodology to manage Italian geodetic datums of the cadastral systems and of the historic maps Applied Geomatics

Timár G., Kocsis B.P., Molnár G., Deligios M., Baiocchi V., Galambos C.,Biszak E.. 2017. Habsburg topographic cartography of the Italian peninsula in the first half of the 19th century. International Cartographic Association, Commission on Cartographic Heritage into the Digital Editor Evangelos Livieratos Proceedings 12th ICA Conference Digital Approaches to Cartographic Heritage, Venice, 26-28 April 2017

Agenzia del Catasto, 2018. Servizio di consultazione della cartografia catastale web map service (wms). https://www.agenziaentrate.gov.it/wps/file/Nsilib/Nsi/Schede/F abbricatiTerreni/Consultazione + cartografia + catastale/Servizio + Consultazione+cartografia/Manuale+consultazione+cartografia/ Documentazione + descrittiva + del + servizio + di + consultazione $+d$ ella+cartografia +catastale+20180611.pdf (last seen online, march 2019) 